\title{
Serum parameters and severity of coronary artery disease in patients with acute coronary syndrome
}

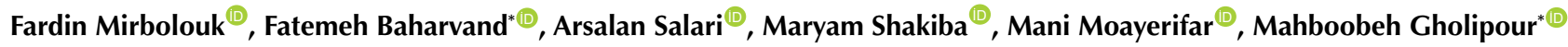 \\ Cardiovascular diseases research Center, Department of Cardiology, Heshmat Hospital, School of Medicine, Guilan University of Medical \\ Sciences, Rasht, Iran
}

*Correspondence to Fatemeh baharvand Email:

ftm_karoon@yahoo.com Mahboobeh Gholipour, Email:

drmgholipur@gmail.com

Received 12 Oct. 2019 Accepted 20 Dec. 2019 Published online 19 Jan. 2020

Keywords: Platelet, Lymphocyte count, Coronary artery disease, Coronary angiography, Atherosclerosis, Inflammation, Biomarker White blood cells

\section{Abstract}

Introduction: Coronary artery disease (CAD) is one of the most common causes of morbidity and mortality in developed countries. SYNTAX (SX) score is a useful index that scores lesion severity during coronary angiography (CA) and can predict the patient's outcome. Recent studies have associated a number of serum parameters with SX score, including platelet volume, and platelet-to-lymphocyte ratio (PLR).

Objectives: We aimed to study the SX score in association with various serum parameters to find a valuable parameter for prediction of CAD severity.

Patients and Methods: This study consisted of 363 patients referred to Heshmat hospital (Rasht) from March 2016 to October 2016 with acute coronary syndrome (ACS). Serum laboratory parameters were measured after 12 hours of fasting. Severity of CAD was evaluated during CA by SX score. The associations were analyzed using multinomial logistic regression model.

Results: The mean age of patients was $63.68 \pm 11.03$ years; since $26.2 \%$ of cases had severe, $43 \%$ had moderate, and $30.8 \%$ had mild CAD. Comparing to mild CAD, the multivariate adjusted model showed higher significant odds of severe CAD for one elevation of platelets (odds ratio $[\mathrm{OR}]=2.18(95 \% \mathrm{Cl}: 1.35-3.50)$, white blood cells (WBCs) $(\mathrm{OR}=1.66,95 \% \mathrm{Cl}: 1.17-2.35)$ RDW (red cell distribution width), (OR=1.59, 95\% Cl: 1.08-2.35) and serum creatinine $(\mathrm{OR}=1.75,95 \% \mathrm{Cl}: 1.16-2.63)$.

Conclusion: Plasma platelets, WBC and RDW and also serum creatinine were all independently correlated with severity of CAD.

\section{Introduction}

Recent advances in treatment modalities have significantly reduced the incidence of myocardial infarction (MI) worldwide. Nevertheless, it is still considered as the major cause of mortality in most developed countries $(1,2)$. In developing countries, acute coronary syndromes (ACSs) are life-threatening conditions which account for approximately one-half of all cardiovascular disease related mortality and upwards of one-third of all deaths globally, after road accidents $(3,4)$.

A considerable number of patients do not reach the hospital in the golden survival time, since patients who survive from MI are prone to recurrence of MI that has higher mortality rates (5). The prognosis of patients with STelevation myocardial infarction (STEMI) is worse in patients who suffer from multivessel disease (6). Therefore, multiple arterial revascularization therapy has been suggested for the affected patients in the minimum time possible (7). Although coronary artery bypass grafting (CABG) is believed as the

\section{Key point}

In a study on 363 patients with acute coronary syndrome (ACS), we found plasma platelets, white blood cells (WBCs) and RDW (red cell distribution width) and also serum creatinine were all independently correlated with the severity of coronary artery disease. In our study, individuals with higher RDW levels had high SYNTAX (SX) score and had more significant lesions simultaneously.

gold standard treatment, its outcome may not be much different from other treatment modalities such as stents with percutaneous coronary intervention (PCI) while all treatment modalities are associated with a considerable risk of mortality and recurrence of MI $(7,8)$.

To distinguish the severity of coronary artery disease (CAD) and select the most appropriate treatment, several imaging modalities have been suggested. In this regard, a recent study has used myocardial perfusion scintigraphy to determine myocardial perfusion extent as an indicator of CAD

\footnotetext{
Copyright $($ ) 2020 The Author(s); Published by Nickan Research Institute. This is an open-access article distributed under the terms of the Creative Commons Attribution License (http://creativecommons.org/licenses/by/4.0), which permits unrestricted use, distribution, and reproduction in any medium, provided the original work is properly cited.
} 
severity (9); however, the gold standard is the conventional coronary angiography (CA) which visualizes the anatomy of coronary vessels (10) It is noteworthy that CA, despite being invasive, is the preferable method because unlike the scintigraphy approach, it reveals the exact anatomy of coronary arteries (11). Likewise, SYNTAX (SX) score was introduced in the SYNTAX study (SYNergy between PCI with TAXus ${ }^{\mathrm{TM}}$ and cardiac surgery) as a useful index that scores lesion severity and complexity during CA, while, is hypothesized to be able to predict the prognosis too (12). Accordingly, it is hypothesized to help to expand the indications of revascularization procedures in complex and high-risk lesions (13).

Previous studies have evaluated SX score and its association with various conditions. Several serum parameters have been investigated to distinguish between severe, moderate, or mild SX scores, including uric acid $(14,15)$, serum levels of iron (16), copper and 25-hydroxy vitamin D (17) as well as serum bilirubin (18). Mean platelet volume (MPV) (19), and platelet-to-lymphocyte ratio (PLR) (20) have also been associated with SX score. It has been suggested that by future studies, cardiologists will be able to predict atherosclerosis by simple serologic tests.

\section{Objectives}

We aimed to study the association of SX score with various serum parameters, to find a valuable parameter for prediction of CAD severity.

\section{Patients and Methods}

\section{Study population}

In this study we recruited patients who referred to Heshmat hospital (Guilan province, north of Iran) from March 2016 to October 2016 with ACS to study the association of blood index and severity of CAD by SX score. The sample size of the study was calculated to be 363 , considering effect size of $0.21, \alpha=0.05$, and power of $95 \%$. Then, patients who were diagnosed with ACS were included. Patients with moderate to severe valvular disorder, patients in decompensated heart failure, cancer or hematological disorders, renal and hepatic failure, active infection, systemic inflammation or auto-immune disease and patients using corticosteroids were excluded. Any patient whose laboratory data was unavailable was also excluded from the study. Additionally, any patient with severe renal dysfunction and acute infection was not included in analysis. In the present study, 5 patients were excluded; 3 patients didn't have accessible laboratory tests, and 1 patient had severe renal dysfunction and the other had acute infection.

The demographic information of patients that were recorded included body mass index (BMI), age, and gender as well as the risk factors, including personal history of MI and stroke, history of PCI, and CABG, personal and family history of cardiac diseases, and current/last 5 years' smoking status. The family history of cardiac diseases was considered positive in first degree relatives younger than 65 in women, and younger than 55 in men. Hypertension was considered positive, when systolic blood pressure (SBP) was more than $140 \mathrm{mmHg}$, and diastolic blood pressure (DBP) was greater than $90 \mathrm{~mm} \mathrm{Hg}$. Positive type 2 diabetes mellitus (T2DM) was diagnosed by FBS $>125 \mathrm{mg} / \mathrm{dL}$ in two measurements, or history of diabetic drugs. Then, a venous blood sample was taken from all participants after 12 hours fasting, and was sent to the laboratory for measurement of cell blood count (CBC) and hematologic indices, and also serum levels of FBS, triglyceride, cholesterol, LDL-c, and HDL-c.

Then, all patients underwent CA by one cardiologist with Siemens device ( Germany), and the severity of CAD was assessed by a blind interventionist who calculated SX score for all patients, based on the involved vessel, and the severity of involvement (21). SX score is defined as the scores for each lesion with $\geq 50 \%$ stenosis in a vessel of $\geq 1.5 \mathrm{~mm}$ diameter by visual assessment. As a result, the patients were categorized into three categories, based on SX score; low SX score $[<22]$, referred to mild CAD, while moderate SX score [22-32], referred to moderate CAD and finally, high SX score [ $>33]$, showed severe CAD. Accordingly, mean level of laboratory parameters was compared among the three mentioned categories, considering the demographics as confounding variables (21). Levels of serum lipids were categorized according to introduced cut-points (published by adult therapeutic panel) as total cholesterol $\leq 240 \mathrm{mg} / \mathrm{dL}, \mathrm{HDL}-\mathrm{c}>40 \mathrm{mg}$ / $\mathrm{dL}, \mathrm{LDL}-\mathrm{c} \geq 160 \mathrm{mg} / \mathrm{dL}, \mathrm{TG} \geq 200 \mathrm{mg} / \mathrm{dL}$ (22).

\section{Ethical consideration}

The research followed the tenets of the Declaration of Helsinki. This paper was extracted from the residential thesis of Fatemeh Baharvand, in the department of cardiology, Heshmat hospital, school of medicine, Guilan University of Medical Sciences. The study was approved by the ethics committee of the Guilan University of Medical Sciences (\#IR.GUMS.REC.1395.165). Additionally, informed consent was obtained from all the patients.

\section{Statistical analysis}

Data were described as frequency (percent) or mean \pm standard deviation. To assess the normal distribution of variables, Kolmogorov-Smirnov test was used. The univariate comparisons were made using t-test, ANOVA, Kruskal-Wallis or chi-square test according to the type and normal distribution of variables. The adjusted odds ratio estimated for marginal significant variables $(P$ value $<0.1)$ using polytomous logistic regression model. All analysis was performed using Stata/SE version 13.1.

\section{Results}

A total of 363 patients (mean age $63.68 \pm 11.03$ years, $52.6 \%$ men) were included in this study. Around $29.8 \%$ were smokers and $15.4 \%$ had a positive history of cardiac 
disease, while $70.2 \%$ had T2DM. Most patients had moderate (43\%) and mild (30.8\%) CAD severity, since $26.2 \%$ of cases had severe CAD. Table 1 demonstrates detailed demographic characteristics of patients according to CAD category based on syntax score. Severe CAD patients were more likely to be older $(P<0.001)$ and with higher prevalence of diabetes and hypertriglyceridemia compared to mild and moderate CAD patients.

Comparison of serum parameters based on SX score revealed statistically significant differences among categories in white blood cell (WBC) count, plasma $\mathrm{Hb}$ (hemoglobin) levels, RDW (red cell distribution width), lymph (lymphocyte) and PLT (platelets) counts, as well as PLR (platelet to lymphocyte ratio) (Table 2). Patients with severe CAD had higher WBC count, lower hemoglobin level, higher RDW, higher platelet level and PLR (Table 2).

The independent associations between each significant variable with severity of CAD were then estimated using polytomous logistic model considering mild CAD as the reference category. The results are presented in Table 3.
Older age and having diabetes were significant independent predictors for both moderate and severe CAD compared to mild CAD. For moderate CAD, the eosinophil level was a significant predictor since one percent elevation of eosinophil level increased the odds of moderate CAD as $43 \%$ compared to mild CAD. Patients with the history of cardiac procedure were about three times more likely to have severe CAD compared to mild CAD. Among blood serum parameters, 1 standard deviation increase in WBC count, RDW, platelet and serum creatinine level significantly increased the odds of severe CAD compared to mild CAD as $66 \%, 59 \%, 118 \%$ and $74 \%$, respectively. Besides, we found that eosinophil counts predict the extent of CAD in 2-3-vessel disease versus 1 vessel disease $(\mathrm{OR}=1.43,95 \% \mathrm{CI}=1.09-1.89$; Table 3$)$.

Further, we investigated the exact diagnostic accuracy of PLR platelet to lymphocyte ratio by ROC curve, when considered at 108.69 for diagnosis of moderate and severe versus mild CAD. We found the sensitivity and specificity, of $49 \%$ and $75 \%$ respectively, and positive predictive

Table 1. Demographic and clinical characteristics of study participants according to syntax severity score of CAD

\begin{tabular}{|c|c|c|c|c|c|}
\hline & $\begin{array}{c}\text { Number } \\
\mathrm{N}=363\end{array}$ & $\begin{array}{c}\text { Mild } \\
\text { No. }(\%)\end{array}$ & $\begin{array}{c}\text { Moderate } \\
\text { No. }(\%)\end{array}$ & $\begin{array}{c}\text { Severe } \\
\text { No. }(\%)\end{array}$ & $P$ value $^{a}$ \\
\hline \multicolumn{6}{|l|}{ Gender } \\
\hline Male & 191 & $64(57)$ & $78(50)$ & $49(51)$ & 0.499 \\
\hline Female & 172 & $48(42)$ & $78(50)$ & $46(48)$ & \\
\hline \multicolumn{6}{|l|}{ Age group (y) } \\
\hline$<63$ & 182 & $75(66)$ & $72(46)$ & $35(36)$ & 0.001 \\
\hline$>63$ & 181 & 37 (33) & $84(53)$ & $60(63)$ & \\
\hline \multicolumn{6}{|l|}{ Smoking } \\
\hline Yes & 108 & 33 (29) & $48(30)$ & $27(28)$ & 0.922 \\
\hline No & 255 & $79(70)$ & $108(69)$ & $68(71)$ & \\
\hline \multicolumn{6}{|l|}{ Diabetes } \\
\hline Yes & 255 & $63(56)$ & $116(74)$ & $76(80)$ & 0.001 \\
\hline No & 108 & 49 (43) & $40(25)$ & $19(20)$ & \\
\hline \multicolumn{6}{|l|}{ Low HDL-c } \\
\hline Yes & 253 & $73(65)$ & $106(67)$ & $74(77)$ & 0.115 \\
\hline No & 110 & $39(34)$ & $50(32)$ & $21(22)$ & \\
\hline \multirow{2}{*}{$\begin{array}{l}\text { Total cholesterol }>200 \\
\text { Total cholesterol }<200\end{array}$} & 331 & 107 (95) & $141(90)$ & $83(87)$ & \multirow{2}{*}{0.106} \\
\hline & 32 & $5(4)$ & $15(9)$ & $12(12)$ & \\
\hline \multicolumn{6}{|l|}{ High TG } \\
\hline Yes & 247 & $81(72)$ & $113(72)$ & $53(55)$ & 0.012 \\
\hline No & 116 & $31(27)$ & $43(27)$ & $42(44)$ & \\
\hline \multicolumn{6}{|l|}{ High LDL-c } \\
\hline Yes & 343 & $110(98)$ & $\begin{array}{c}145(92) \\
11(7)\end{array}$ & $88(95)$ & 0.15 \\
\hline No & 20 & $2(1.7)$ & & $7(7)$ & \\
\hline \multicolumn{6}{|l|}{ Family history } \\
\hline Yes & 41 & $9(8)$ & $20(12)$ & $12(12)$ & 0.423 \\
\hline No & 322 & $103(91)$ & $136(78)$ & $83(87)$ & \\
\hline \multicolumn{6}{|l|}{ CVD } \\
\hline Yes & 273 & $87(77)$ & $125(80)$ & $61(64)$ & 0.014 \\
\hline No & 90 & $25(22)$ & 31 (19) & 34 (35) & \\
\hline \multicolumn{6}{|c|}{ History of cardiac procedure } \\
\hline Yes & 319 & $105(93)$ & $138(88)$ & $76(80)$ & 0.01 \\
\hline No & 44 & $7(6)$ & $18(11)$ & $19(20)$ & \\
\hline
\end{tabular}

HDL; high density lipoprotein (mg/dL), TG; triglyceride (mg/dL), LDL; low density lipoprotein (mg/dL), CVD; myocardial infarction and stroke, cardiac procedure; percutaneous coronary intervention and coronary artery bypass graft. Total cholesterol is in $\mathrm{mg} / \mathrm{dL}$.

${ }^{a}$ Chi-square. 
Table 2. Comparison of serum level of laboratory indices based on the SX score categories in the study population

\begin{tabular}{|c|c|c|c|c|c|}
\hline Serum parameter & SX Score & Number & Mean \pm SD & Test value & $P$ value \\
\hline \multirow{3}{*}{ WBC, $10^{9} / \mathrm{L}$} & Mild & 112 & $9627.3 \pm 3238$ & \multirow{3}{*}{$F=3.64$} & \multirow{3}{*}{0.027} \\
\hline & Moderate & 156 & $10504.1 \pm 3620$ & & \\
\hline & Severe & 95 & $10868.7 \pm 3477.4$ & & \\
\hline \multirow{3}{*}{$\mathrm{RBC}, 10^{6} / \mathrm{dL}$} & Mild & 112 & $4.62 \pm 0.57$ & \multirow{3}{*}{$F=0.701$} & \multirow{3}{*}{0.497} \\
\hline & Moderate & 156 & $4.7 \pm 0.52$ & & \\
\hline & Severe & 95 & $4.6 \pm 0.6$ & & \\
\hline \multirow{3}{*}{ Hemoglobin, g/dL } & Mild & 112 & $13.52 \pm 0.57$ & \multirow{3}{*}{$F=3.44$} & \multirow{3}{*}{0.033} \\
\hline & Moderate & 156 & $13.66 \pm 1.78$ & & \\
\hline & Severe & 95 & $8.13 \pm 1.63$ & & \\
\hline \multirow{3}{*}{ Hematocrit (Hct), \% } & Mild & 112 & $41.6 \pm 5$ & \multirow{3}{*}{$F=0.652$} & \multirow{3}{*}{0.522} \\
\hline & Moderate & 156 & $41.46 \pm 5.03$ & & \\
\hline & Severe & 95 & $72 / 40 \pm 08 / 5$ & & \\
\hline \multirow{3}{*}{$\mathrm{MCV}(\mathrm{fl})$} & Mild & 112 & $77.32 \pm 19.58$ & \multirow{3}{*}{$F=1.24$} & \multirow{3}{*}{0.289} \\
\hline & Moderate & 156 & $79.41 \pm 15.01$ & & \\
\hline & Severe & 95 & $75.78 \pm 20.8$ & & \\
\hline \multirow{3}{*}{$\mathrm{MCH}$} & Mild & 112 & $27.87 \pm 2.52$ & \multirow{3}{*}{$\mathrm{F}=0.955$} & \multirow{3}{*}{0.386} \\
\hline & Moderate & 156 & $27.4 \pm 3.24$ & & \\
\hline & Severe & 95 & $27.72 \pm 2.5$ & & \\
\hline \multirow{3}{*}{$\mathrm{MCHC}$} & Mild & 112 & $31.64 \pm 4.29$ & \multirow{3}{*}{$F=0.279$} & \multirow{3}{*}{0.757} \\
\hline & Moderate & 156 & $31.39 \pm 3.72$ & & \\
\hline & Severe & 95 & $31.2 \pm 11.5$ & & \\
\hline \multirow{3}{*}{ RDW } & Mild & 112 & $12.94 \pm 0.65$ & & \\
\hline & Moderate & 156 & $13.3 \pm 1.29$ & $F=7.77$ & 0.001 \\
\hline & Severe & 95 & $13.55 \pm 1.24$ & & \\
\hline & Mild & 112 & $157.4 \pm 63$ & & \\
\hline Eosinophil, $10^{9} / \mathrm{L}$ & Moderate & 156 & $173.9 \pm 60.6$ & $F=2.49$ & 0.084 \\
\hline & Severe & 95 & $167.4 \pm 53.8$ & & \\
\hline & Mild & 112 & $156.8 \pm 59.6$ & & \\
\hline Monocyte, $10^{9} / \mathrm{L}$ & Moderate & 156 & $160.4 \pm 47.45$ & $\mathrm{~F}=0.217$ & 0.805 \\
\hline & Severe & 95 & $156.6 \pm 54.17$ & & \\
\hline & Mild & 112 & $2957 \pm 1898$ & & \\
\hline Lymphocytes, $10^{9} / \mathrm{L}$ & Moderate & 156 & $2491.2 \pm 1338.3$ & $F=3.22$ & 0.041 \\
\hline & Severe & 95 & $2776.3 \pm 1246.1$ & & \\
\hline & Mild & 112 & $7470 \pm 3544$ & & \\
\hline Neutrophil, $10^{9} / \mathrm{L}$ & Moderate & 156 & $8251.8 \pm 4000.7$ & $F=1.47$ & 0.23 \\
\hline & Severe & 95 & $8218.2 \pm 4283$ & & \\
\hline & Mild & 112 & $216521 \pm 57564$ & & \\
\hline PLT, $10^{9} / \mathrm{L}$ & Moderate & 156 & $225919.8 \pm 57564$ & $F=10.05$ & 0.0001 \\
\hline & Severe & 95 & $255263.1 \pm 73782.2$ & & \\
\hline & Mild & 112 & $10.28 \pm 0.83$ & & \\
\hline MPV & Moderate & 156 & $10.22 \pm 0.92$ & $F=1.09$ & 0.336 \\
\hline & Severe & 95 & $10.08 \pm 1.2$ & & \\
\hline & Mild & 112 & $90.62 \pm 6.46$ & & \\
\hline PITlymphoryte ratin & Moderate & 156 & $109.67 \pm 54.54$ & $F-481$ & $0 \cap 09$ \\
\hline PLinympmocyle tanio & Severe & 95 & $106.28 \pm 50.13$ & $r=4.01$ & 0.009 \\
\hline & Mild & 112 & $0.99 \pm 0.22$ & & \\
\hline Plasma creatinine $(m o / d n)$ & Moderate & 156 & $1.08 \pm 0.29$ & $E=738$ & 0001 \\
\hline & Severe & 95 & $1.15 \pm 0.38$ & & \\
\hline
\end{tabular}

MCV, mean corpuscular volume; $\mathrm{MCH}$, mean corpuscular hemoglobin; $\mathrm{MCHC}$, mean corpuscular hemoglobin concentration; RDW, red blood cell distribution width; MPV, mean platelet volume; WBC, white blood cell; RBC, red blood cell; PLT, platelet;

value and negative predictive value of $81.5 \%$, and $39.6 \%$, respectively, with statistical insignificance (Figure 1).

\section{Discussion}

We investigated the role of hematological indices; WBC, RDW, and PLT indices, like PLR, MPV in the cases of ACS. We aimed to find the association between the mentioned parameters and the extent of CAD. We detected that WBC, serum platelet and RDW are separately correlated with the presence and severity of CAD.

In the pathophysiology of ACS, an increased systemic and local inflammation plays a key role. A key role in the progress of atherosclerosis associated with inflammation, and WBC count is a biomarker of inflammation. 
Table 3. Multinomial logistic regression model of predictors with severity of CAD

\begin{tabular}{|c|c|c|c|c|c|c|}
\hline CAD category* & Independent predictors & Adjusted OR & $95 \% \mathrm{Cl}$ & Standard error & Wald statistic & $P$ value \\
\hline \multirow{13}{*}{ Moderate } & Age $>63$ years & 1.90 & $1.08-3.36$ & 0.55 & 2.24 & 0.025 \\
\hline & Diabetes & 2.21 & $1.25-3.90$ & 0.639 & 2.76 & 0.006 \\
\hline & CVD & 0.83 & $0.43-1.61$ & 0.28 & -0.54 & 0.589 \\
\hline & History of cardiac procedure & 2.01 & $0.70-5.27$ & 1.07 & 1.31 & 0.190 \\
\hline & High TG & 0.91 & $0.49-1.69$ & 0.28 & 0.29 & 0.77 \\
\hline & $\begin{array}{l}\mathrm{ZWBC} \\
1 \mathrm{SD} \text { increase }\end{array}$ & 1.22 & $0.91-1.64$ & 0.18 & 1.36 & 0.173 \\
\hline & $\begin{array}{l}\mathrm{zHB} \\
1 \mathrm{SD} \text { increase }\end{array}$ & 1.05 & $0.80-1.39$ & 0.14 & 0.41 & 0.68 \\
\hline & $\begin{array}{l}\text { zRDW } \\
1 \mathrm{SD} \text { increase }\end{array}$ & 1.42 & $0.99-2.04$ & 0.26 & 1.96 & 0.05 \\
\hline & $\begin{array}{l}\text { Zplatelet } \\
1 \text { SD increase }\end{array}$ & 0.95 & $0.63-1.43$ & 0.19 & -0.22 & 0.825 \\
\hline & $\begin{array}{l}\mathrm{ZPLR} \\
1 \mathrm{SD} \text { increase }\end{array}$ & 1.24 & $0,74-2.09$ & 0.330 & 0.83 & 0.40 \\
\hline & $\begin{array}{l}Z \text { creatinine } \\
1 \mathrm{SD} \text { increase }\end{array}$ & 1.53 & $0.98-2.07$ & 0.27 & 1.87 & 0.061 \\
\hline & $\begin{array}{l}\text { Z Lymphocyte } \\
1 \text { SD increase } \\
\end{array}$ & 0.76 & $0.51-1.12$ & 0.15 & -1.37 & 0.170 \\
\hline & $\begin{array}{l}\text { Z eosinophil } \\
1 \text { SD increase }\end{array}$ & 1.43 & $1.09-1.89$ & 0.20 & 2.57 & 0.010 \\
\hline \multirow{13}{*}{ Severe } & Age $>63$ years & 2.51 & $1.26-4.96$ & 0.87 & 2.65 & 0.008 \\
\hline & Diabetes & 3.26 & $1.53-6.93$ & 1.25 & 3.08 & 0.002 \\
\hline & CVD & 1.77 & $0.85-3.68$ & 0.66 & 1.54 & 0.123 \\
\hline & History of cardiac procedure & 2.92 & $0.94-9.00$ & 1.67 & 1.87 & 0.006 \\
\hline & High TG & 1.98 & $0.97-4.04$ & 0.72 & 1.88 & 0.059 \\
\hline & $\begin{array}{l}\mathrm{zWBC} \\
1 \mathrm{SD} \text { increase }\end{array}$ & 1.66 & $1.17-2.35$ & 0.29 & 2.87 & 0.004 \\
\hline & $\begin{array}{l}\mathrm{zHB} \\
1 \mathrm{SD} \text { increase }\end{array}$ & 0.72 & $0.52-1.01$ & 0.122 & -1.89 & 0.059 \\
\hline & $\begin{array}{l}\text { Z RDW } \\
1 \mathrm{SD} \text { increase }\end{array}$ & 1.59 & $1.08-2.34$ & 0.315 & 2.36 & 0.018 \\
\hline & $\begin{array}{l}\text { Z platelet } \\
1 \mathrm{SD} \text { increase }\end{array}$ & 2.18 & $1.35-3.50$ & 0.527 & 3.23 & 0.001 \\
\hline & $\begin{array}{l}\mathrm{ZPLR} \\
1 \mathrm{SD} \text { increase }\end{array}$ & 0.63 & $0.33-1.18$ & 0.230 & -1.43 & 0.153 \\
\hline & $\begin{array}{l}Z \text { creatinine } \\
1 \mathrm{SD} \text { increase } \\
\end{array}$ & 1.74 & $1.16-2.62$ & 0.362 & 2.69 & 0.007 \\
\hline & $\begin{array}{l}\text { Z Lymphocyte } \\
1 \text { SD increase }\end{array}$ & 0.69 & $0.42-1.13$ & 0.172 & -1.45 & 0.146 \\
\hline & $\begin{array}{l}Z \text { eosinophil } \\
1 \text { SD increase }\end{array}$ & 1.17 & $0.83-1.64$ & 0.202 & 0.92 & 0.485 \\
\hline
\end{tabular}

*The reference category is mild CAD defined as syntax score $<22$

Additionally, WBC has a crucial role from the beginning of the development of atherosclerosis(23). The association between WBC count and the severity of CAD has been detected by Kose et al (24). In the present study, we found that eosinophil counts predict the extent of CAD in $2-3$ vessels disease versus one vessel disease.

Zhao et al showed that the total WBC count was an independent risk factor for death and major adverse cardiac or cerebrovascular events in patients with triplevessel CAD in long-term follow-up (25).

Similar to our study, Kim et al and Uysal et al, found that WBC count to be a predictor of the development of atherosclerosis $(26,27)$. Based on the findings of our study, the WBC counts were detected to be statistically different between the groups who categorized according to SX score $(P=0.004)$. In this situation, the relationship between high values of WBC count and severity of CAD was explained by the inflammatory structure of coronary artery involvement.

Increased PLT count has been demonstrated to stimulate inflammation and may lead to active atherosclerosis(28). Inappropriate platelet activation is an important pathogenic component of thrombosis at the site of vascular injury which leads to ACS (29). Platelet counts are also meaningfully correlated with platelet activation (30). This correlation might be described by this fact that the metabolic and enzymatic activation of PLT are increased. Moreover, there is a heightened secretion of mediators from the hemostatically active PLTs. In the development of atherosclerotic lesions, PLTs are interacted with chemotactic substances, inflammatory and mitogenic substances. Based on the current findings, there was a rise 


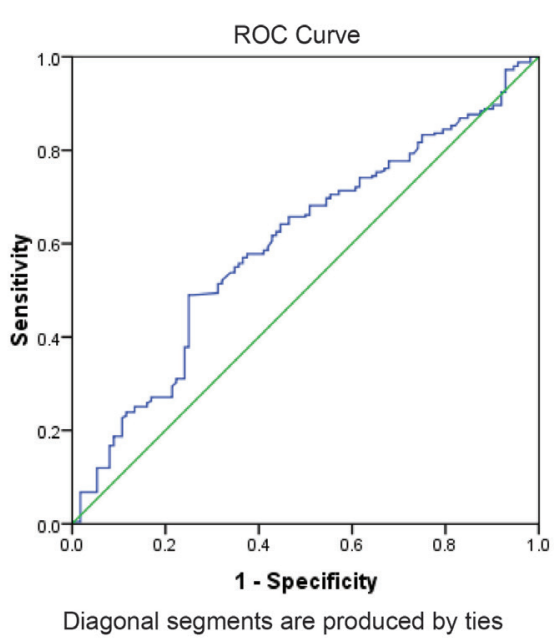

Figure 1. ROC curve, according to PLR index, to determine appropriate cutoff point for prediction of moderate and severe, versus mild CAD in the study population.

in platelet counts with the rising proportion of coronary stenosis. PLR has been suggested to be associated with severity of CAD in the previous studies, suggesting PLR as an independent risk factor for mortality of patients with STEMI (31) and non-STEMI (32).

Heightened thrombocyte activation and a prothrombotic state may be caused by a higher PLR (28). It has been indicated that PLR is associated with various inflammatory markers (33). As recently demonstrated, PLR may be an independent predictor of coronary vessel disease events because PLR is heightened in the multi-vessel disease (2and 3-vessel) groups compared with the 1-vessel group, however, it was statistically insignificant. As known, the mild atherosclerosis group has more severe inflammation, thus there was no difference between mild atherosclerosis with other groups.

RDW is a measurement of the range of variation in size of red blood cell volume (anisocytosis) used in the differential diagnosis of anemia as part of red cell indices. In recent years, different studies have reported the importance of RDW as a predictor of poor clinical outcomes in the settings of various diseases, including CAD. Patients with higher RDW values who have reduced red blood cell deformability suffering from a negative effect on blood flow via the microcirculation, resulting in the deduction of oxygen supply at the tissue level, especially among patients who had a history for MI treated with urgent revascularization (34).

Danese et al showed that elevated RDW in a patient with CAD leads to an elevated risk of heart failure (35). RDW was detected to be helpful in triaging patients with nonST-elevation ACS in a cohort of 251 patients referred to coronary care unit over one year period by Tenekecioglu et al (36).

\section{Conclusion}

In this study we found plasma PLT, WBC count and
RDW and also serum creatinine were all independently correlated with severe CAD. In our research, individuals with higher RDW values had high SX score and had more significant lesions simultaneously.

\section{Study limitations}

Potential limitations of the present study include limited sample size, and selection of patients who referred to one center that limits the generalization of the results. In addition, only major coronary arteries are detected by $\mathrm{CA}$ and it cannot assess microvascular diseases. Also, to determine the stage and grade of coronary atherosclerosis, intravascular ultrasonography or optical coherence tomography are required that were beyond the objectives of the present study.

\section{Authors' contribution}

Study concept and design; MG, AS and FM. Acquisition of data; FB and MM. Statistical analysis; MSh. Drafting of the manuscript; FB. Critical revision of the manuscript for important intellectual content; all authors. All authors read and approved the final version.

Conflicts of interest

All authors declare that they have no conflict of interest.

\section{Ethical considerations}

Ethical issues (including plagiarism, misconduct, data fabrication, falsification, double publication or submission and redundancy) have been completely observed by the authors.

\section{Funding/Support}

This study was approved and granted by Guilan University of Medical Sciences (\#95052308).

\section{References}

1. Shroff GR, Li S, Herzog CA. Trends in mortality following acute myocardial infarction among dialysis patients in the United States over 15 years. J Am Heart Assoc. 2015;4:e002460. doi: 10.1161/JAHA.115.002460.

2. Söğüt $E$, Kadı H, Karayakalı M, Mertoğlu C. The association of plasma vitamin A and E levels with coronary collateral circulation. Atherosclerosis. 2015;239:547-51. doi: 10.1016/j. atherosclerosis.2015.02.029.

3. Abu HO, Lapane KL, Waring ME, Ulbricht CM, Devereaux RS, McManus DD, et al. Religious practices and long-term survival after hospital discharge for an acute coronary syndrome. PloS one. 2019;14:e0223442. doi: 10.1371/journal.pone.0223442.

4. Sanchis-Gomar F, Perez-Quilis C, Leischik R, Lucia A. Epidemiology of coronary heart disease and acute coronary syndrome. Ann Transl Med. 2016;4:256. doi:10.21037/ atm.2016.06.33.

5. Gerber $\mathrm{Y}$, Weston SA, Jiang R, Roger VL. The changing epidemiology of myocardial infarction in Olmsted County, Minnesota, 1995-2012. Am J Med. 2015;128:144-51. doi: 10.1016/j.amjmed.2014.09.012.

6. Hasun M, Weidinger F. Culprit Vessel Only Versus Complete Revascularisation in Patients with ST-Segment Elevation Myocardial Infarction-Should we Stay or Stage? Interv Cardiol. 2018;13:129-134. doi: 10.15420/icr.2018.13.2.

7. Spadaccio $\mathrm{C}$, Benedetto $U$. Coronary artery bypass grafting $(\mathrm{CABG})$ vs. percutaneous coronary intervention $(\mathrm{PCl})$ in the treatment of multivessel coronary disease: quo vadis? - a review of the evidences on coronary artery disease. Ann Cardiothorac 
Surg. 2018;7:506-515. doi: 10.21037/acs.2018.05.17.

8. Vaidya SR, Devarapally SR, Arora S. Infarct related artery only versus complete revascularization in ST-segment elevation myocardial infarction and multi vessel disease: a metaanalysis. Cardiovasc Diagn Ther. 2017;7:16-26. doi: 10.21037/ cdt.2016.08.06.

9. Ozdemir S, Barutcu A, Gazi E, Tan YZ, Turkon H. The relationship between some complete blood count parameters and myocardial perfusion: A scintigraphic approach. World J Nucl Med. 2015;14:197-201. doi: 10.4103/14501147.163253.

10. Marcu CB, van Rossum AC. Coronary Artery Bypass Graft Imaging and Assessment of Flow. J Cardiovasc Magn Reson. 2019;21:325-34. e2. doi: 10.1016/B978-0-323-415613.00027-6.

11. Takei H, Sano R, Takahashi Y, Takahashi K, Kominato Y, Tokue $\mathrm{H}$, et al. Usefulness of coronary postmortem computed tomography angiography to detect lesions in the coronary artery and myocardium in cases of sudden death. Leg Med (Tokyo). 2018;30:46-51. doi: 10.1016/j.legalmed.2017.11.005.

12. El Kersh AM, Reda AA, El Hadad MG, El-Sharnouby KH. Correlation between SYNTAX Score and Pattern of Risk Factors in Patients Referred for Coronary Angiography in Cardiology Department, Menoufia University. World J Cardiovasc Dis. 2018;8:431-439. doi: 10.4236/wjcd.2018.88042.

13. Adar A, Onalan O, Cakan F. Relationship between ST-Segment Shifts in Lead aVR and Coronary Complexity in Patients with Acute Coronary Syndrome. Acta Cardiol Sin. 2019;35: 11-19. doi: 10.6515/ACS.201901_35(1).20180622C.

14. Ekici B, Kütük U, Alhan A, Töre HF. The relationship between serum uric acid levels and and angiographic severity of coronary heart disease. Kardiol Pol. 2015;73:533-8. doi: 10.5603/KP.a2015.0024

15. Xiong Z, Zhu C, Qian X, Zhu J, Wu Z, Chen L. Predictors of clinical SYNTAX score in coronary artery disease: serum uric acid, smoking, and Framingham risk stratification. J Invasive Cardiol. 2011;23:501-4.

16. Ruhe J, Waldeyer C, Ojeda F, Altay A, Schnabel RB, Schafer $\mathrm{S}$, et al. Intrinsic Iron Release Is Associated with Lower Mortality in Patients with Stable Coronary Artery Disease-First Report on the Prospective Relevance of Intrinsic Iron Release. Biomolecules. 2018;8:72. doi: 10.3390/biom8030072

17. Baktır AO, Doğan Y, Şarlı B, Şahin Ö, Demirci E, Akpek M, et al. Relationship between serum 25-hydroxyvitamin D levels and the SYNTAX score in patients with acute coronary syndrome. Anatol J Cardiol. 2017;17: 293-297. doi: 10.14744/ AnatolJCardiol.2016.6977.

18. Chang $\mathrm{CC}$, Hsu CY, Huang PH, Chiang $\mathrm{CH}$, Huang SS, Leu $\mathrm{HB}$, et al. Association of serum bilirubin with SYNTAX score and future cardiovascular events in patients undergoing coronary intervention. Acta Cardiol Sin. 2016;32:412-419. doi: 10.6515/acs20150708c.

19. Ekici B, Erkan AF, Alhan A, Sayın I, Aylı M, Töre HF. Is mean platelet volume associated with the angiographic severity of coronary artery disease? Kardiol Pol. 2013;71:832-838. doi: 10.5603/KP.2013.0195.

20. Kurtul A, Murat SN, Yarlioglues M, Duran M, Ergun G, Acikgoz SK, et al. Association of platelet-to-lymphocyte ratio with severity and complexity of coronary artery disease in patients with acute coronary syndromes. Am J Cardiol. 2014;114:9728. doi: 10.1016/j.amjcard.2014.07.005

21. SWGOh. SYNTAX score calculator. 2017; http://www. syntaxscore.com/calculator/start.htm.

22. Caoab J DS. Recent AHA/ACC guidelines on cholesterol management expands the role of the clinical laboratory. Clin Chim Acta. 2019;495:82-4. doi: 10.1016/j.cca.2019.04.002.

23. Moriya J. Critical roles of inflammation in atherosclerosis. Cardiol. 2019;73:22-7. doi: 10.1016/j.jjcc.2018.05.010.

24. Kose N, Akin F, Yildirim T, Ergun G, Altun I. The association between the lymphocyte-to-monocyte ratio and coronary artery disease severity in patients with stable coronary artery disease. Eur Rev Med Pharmacol Sci. 2019;23:2570-5. doi: 10.26355/eurrev_201903_17406.

25. Zhao X, Jiang L, Xu L, Tian J, Xu Y, Zhao Y, et al. Predictive value of in-hospital white blood cell count in Chinese patients with triple-vessel coronary disease. Eur J Prev Cardiol. 2019:26:872-82 doi: 10.1177/2047487319826398.

26. Kim JH, Lim S, Park KS, Jang HC, Choi SH. Total and differential WBC counts are related with coronary artery atherosclerosis and increase the risk for cardiovascular disease in Koreans. PloS one. 2017;12:e0180332. doi: 10.1371/journal.pone.0180332.

27. Uysal HB, Dağlı B, Akgüllü C, Avcil M, Zencir C, Ayhan M, et al. Blood count parameters can predict the severity of coronary artery disease. Korean J Intern Med. 2016;31:1093-1100. doi: 10.3904/kjim.2015.199.

28. Gary T, Pichler M, Belaj K, Hafner F, Gerger A, Froehlich H, et al. Platelet-to-lymphocyte ratio: a novel marker for critical limb ischemia in peripheral arterial occlusive disease patients. PLoS One. 2013;8:e67688. doi: 10.1371/journal.pone.0067688.

29. Li W, Gigante A, Perez-Perez M-J, Yue H, Hirano M, McIntyre $\mathrm{TM}$, et al. Thymidine phosphorylase participates in platelet signaling and promotes thrombosis. Circ Res. 2014;115:9971006. doi: 10.1161/CIRCRESAHA.115.304591.

30. Würtz $M$, Hvas A-M, Kristensen SD, Grove EL. Platelet aggregation is dependent on platelet count in patients with coronary artery disease. Thromb Res. 2012;129:56-61. doi: 10.1016/j.thromres.2011.08.019.

31. Temiz A, Gazi E, Güngör Ö, Barutçu A, Altun B, Bekler A, et al. Platelet/lymphocyte ratio and risk of in-hospital mortality in patients with ST-elevated myocardial infarction. Med Sci Monit. 2014;20: 660-665. doi: 10.12659/MSM.890152.

32. Azab B, Shah N, Akerman M, McGinn JT. Value of platelet/ lymphocyte ratio as a predictor of all-cause mortality after nonST-elevation myocardial infarction. J Thromb Thrombolysis. 2012;34:326-34. doi: 10.1007/s11239-012-0718-6.

33. Turkmen K, Erdur FM, Ozcicek F, Ozcicek A, Akbas EM, Ozbicer A, et al. Platelet-to-lymphocyte ratio better predicts inflammation than neutrophil-to-lymphocyte ratio in end-stage renal disease patients. Hemodial Int. 2013;17:391-6. doi: 10.1111/hdi.12040.

34. Bujak K, Wasilewski J, Osadnik T, Jonczyk S, Kołodziejska A, Gierlotka M, et al. The prognostic role of red blood cell distribution width in coronary artery disease: a review of the pathophysiology. Dis Markers. 2015;2015:824624. doi: 10.1155/2015/824624.

35. Danese E, Lippi G, Montagnana M. Red blood cell distribution width and cardiovascular diseases. J Thorac Dis. 2015;7:E402. doi: 10.3978/j.issn.2072-1439.2015.10.04.

36. Tenekecioglu E, Yilmaz M, Yontar OC, Bekler A, Peker $\mathrm{T}$, Karaagac $\mathrm{K}$, et al. Red blood cell distribution width is associated with myocardial injury in non-ST-elevation acute coronary syndrome. Clinics (Sao Paulo). 2015;70:18-23. doi: 10.6061/clinics/2015(01)04. 